\title{
FACADE INTEGRATION OF SOLAR THERMAL COLLECTORS: A BREAKTHROUGH?
}

\author{
Christian Roecker, MariaCristina Munari-Probst, Estelle de Chambrier, Andreas Schueler, Jean-Louis Scartezzini \\ Ecole Polytechnique Fédérale de Lausanne (EPFL) \\ Laboratoire d'Energie Solaire et de Physique du Bâtiment \\ Bât. LE, Station 18 \\ CH-1015 Lausanne, Switzerland \\ christian.roecker@epfl.ch
}

\begin{abstract}
One main barrier to the acceptability of façade use of solar thermal collectors is their black appearance and the visibility of piping or absorber irregularities through the glazing. To facilitate façade integration, a project was set up to develop selective filters reflecting only a small part of the solar spectrum in the visible range while letting the rest of the radiation heat the absorber. These filters were successfully produced and, combined with a diffusing glass treatment, have achieved the desired masking effect with minor impact on the collector efficiency (less than $10 \%)$. Glasses of various colours combined with several diffusing finishing (acid etching, structured glass etc...) can be produced that are able to hide the absorber. Such glazings will allow the use of the same product both in front of façade areas equipped with solar absorbers (as collector external glass) and in front of the non exposed areas (as façade cladding), opening the way to a broad variety of active façade designs. The active elements can then be positioned at will on the exposed areas, and their quantity determined only by thermal needs. By freeing the dimension of the façade area that can be clad with this glazing from the thermally needed surface for collectors, a major step to help architects use solar thermal on facades has been taken.
\end{abstract}

\section{INTRODUCTION}

Façade integration of solar thermal collectors is still very rare, even though it would greatly increase the potential area available for solar thermal installations. One main obstacle to façade implementation is the difficulty to architecturally integrate presently available collectors, mainly targeted to roof implementation and developed just as technical elements for energy production. In the major field of glazed collectors, a fundamental integration issue is the aesthetic problem posed by the transparency of the glazing: the black and irregular surfaces of solar absorbers and piping visible through the front glass are hardly acceptable in a building façade. Added to the fact that the freedom in the choice of the absorbers' dimensions is often very limited, this makes the façade integration of solar collectors even more problematic.

The work presented here aims at increasing collector integrability into facades by transforming the solar collector into a multifunctional building element used as façade cladding and heat collector.

\section{THE IDEA: HIDE THE ABSORBER / COLOUR THE GLAZING}

One way to overcome both problems, the colour and irregularities of absorber, would be to hide it behind a glass that should be non-transparent, but still leave the solar radiation pass through! Working on the visible part of the solar spectrum, the characteristics of the desired "screen" can be defined: a filter reflecting only a very narrow band in the visible range while letting the rest of the solar spectrum go through (fig.1). As the reflected part of the spectrum is narrow, it will induce only low losses, but will have a visible colour, determined by the position of the reflected peak in the photopic range. The result will be a strong coloured reflection from the treated glass, masking any dark elements behind it (Fig. 2). 


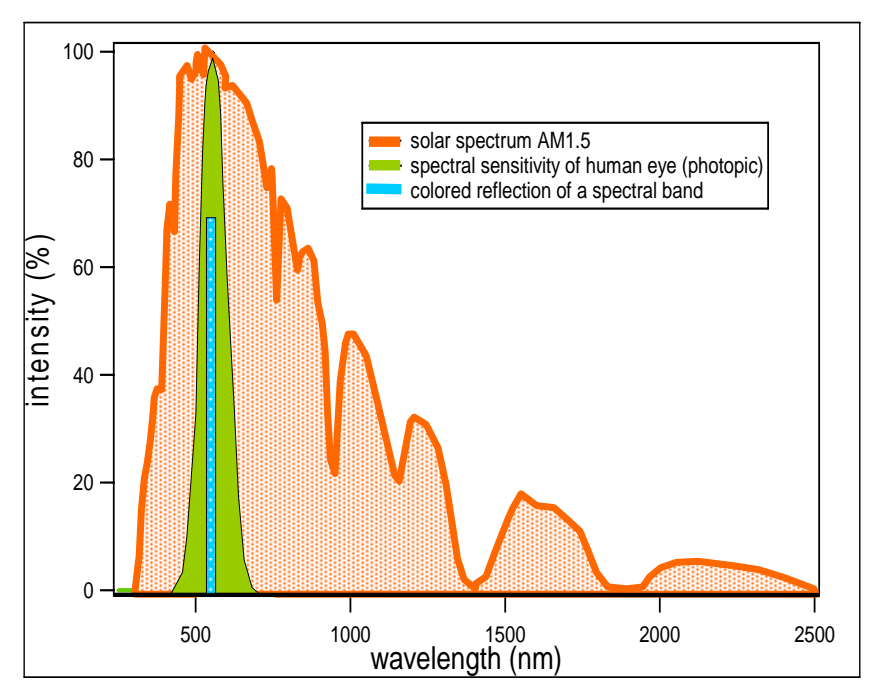

Fig. 1: The idea: Reflect a narrow band in the visible range.

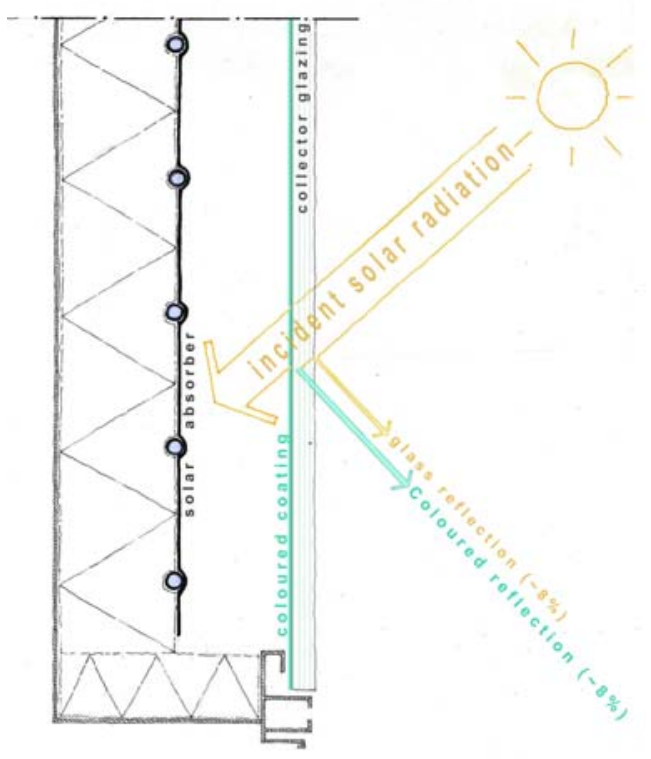

Fig. 2: Principle of operation: coloured reflection.

\section{THE TECHNOLOGY /OBTAINED COLOURS / LIMITS}

The technology used to produce the desired effect is based on thin films interference filters [ref 5,6,7], allowing a fine tuning of the peak spectral position and intensity. The successive layers of $\mathrm{TiO}_{2}$ and $\mathrm{SiO}_{2}$ can be deposited either by dip-coating or by magnetron sputtering. A large palette of colours can be obtained (Fig. 3) by varying the thickness and/or the number of the various layers. Due to the very principle of these filters (interferences) some colours present an important angle dependency that can limit their use in an architectural environment, or can be used in a specific context. In the case of a blue reflection, the colour remains stable for any vision angle.

More important is the fact that the masking effect takes place when reflecting the light, and in the situation of an observer looking at the collector with no direct light to be reflected, the absorber would remain visible. While the results at this stage were already promising and can be used to produce the coloured reflection, the problem of the remaining transparency led to the next development step.

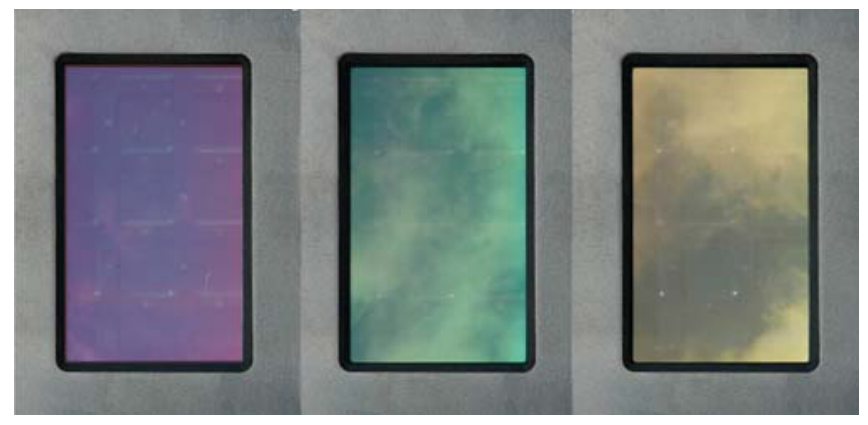

Fig. 3: Examples of obtainable colours

\section{FURTHER STEP: OUTSIDE GLASS TREATEMENT}

To obtain the desired masking effect in all conditions, the coloured coating deposited on the inner side of the glazing is combined with a diffusing surface treatment on the outer side. The strategy to try a partial masking of the absorbers' visual defects by using a structured glass alone has already been used by some manufacturers, but with mixed results as the added fuzziness doesn't completely suppress the vision to the inside of the collector.

Different glass qualities or glass treatments, like structured glass (e.g.. pyramidal), frosted glass, acid etching, sand or stone projection were tested in combination with the developed selective filters.

The results showed that the use of one of these diffusing methods is the ideal complement to the reflecting layer, as this overcomes the problem of "missing reflexion" while reducing slightly the colour angle dependency. Moreover, the choice offered for the outer surface of the glass emphasises the flexibility of the new integrated collector as multifunctional building element.

The Fig. 4 shows the principle of the double treatment 


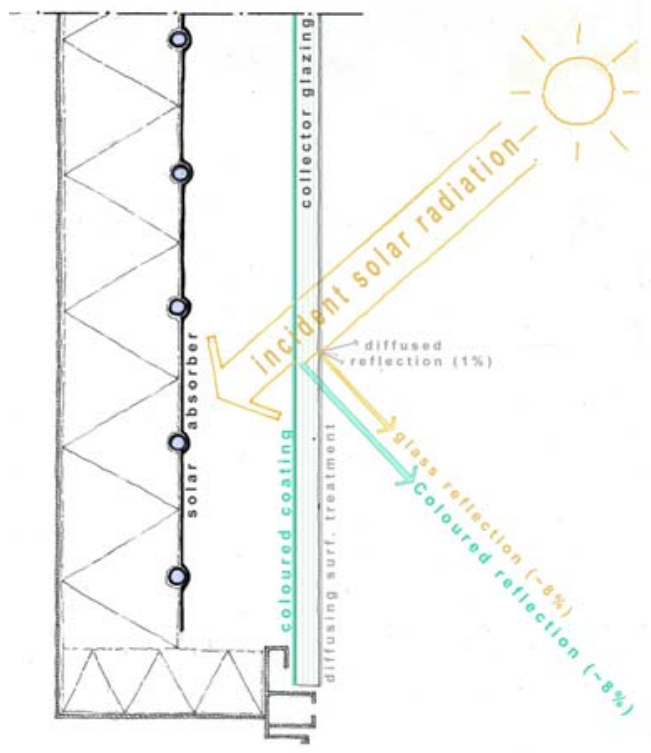

Fig. 4: The double treatment: diffusing layer added.

To demonstrate the impact on the visibility of the absorber obtained after the 2 glass treatments, the Fig. 5 (a-c) show the three states of the glazing on a small collector box.

Fig. 5 a shows the untreated white glass, and the highly visible absorber

Fig. $5 \mathrm{~b}$ shows the glass with the interference filter (blue hue), and the partly masked same absorber

Fig. 5 c shows the final glass, with filter and standard acid etching, invisible same absorber behind

The glass treatments can also be done in a different order, adding the specific interference filter coating to a standard frosted white glass.

\section{RESULTING GLAZING}

The resulting glazing is a product that looks very similar to glass already used to cover opaque parts of the façade, with a coloured appearance and a textured or frosted finish. In the case of acid etching, the freedom offered by this technique can be used to propose patterns or even customized texts or logos. These motives can be produced either by varying the intensity of the acid etching or by leaving small parts untreated (Fig. $5 \mathrm{~d}$ and e).

With these glazings the parts of the façade that produce energy can also be aesthetic or communicate a message.

\section{VISION: APPLICATION SIMULATIONS}

Thanks to this new approach, the solar thermal collector mounted in façade can become a multifunctional building element, with the added function of glass façade cladding. As these glasses are visually non transparent when mounted in front of absorbers or other dark backgrounds, they can cover all opaque parts of the façade, be they equipped with absorbers or not. The active elements can then be positioned at will on the exposed areas, and their quantity determined only by thermal needs. Added to the freedom already offered in terms of colours and surface treatments, this new independency of the thermal and architectural needs finally offers architects the adequate level of façade composition flexibility.

In the following example of a school building in Pully near Lausanne (Switzerland), existing glass façade elements have been replaced (Photoshop) by the new product. Areas equipped or not with collectors (Fig. 8-b) can be covered with the same glass (Fig. 8-a).

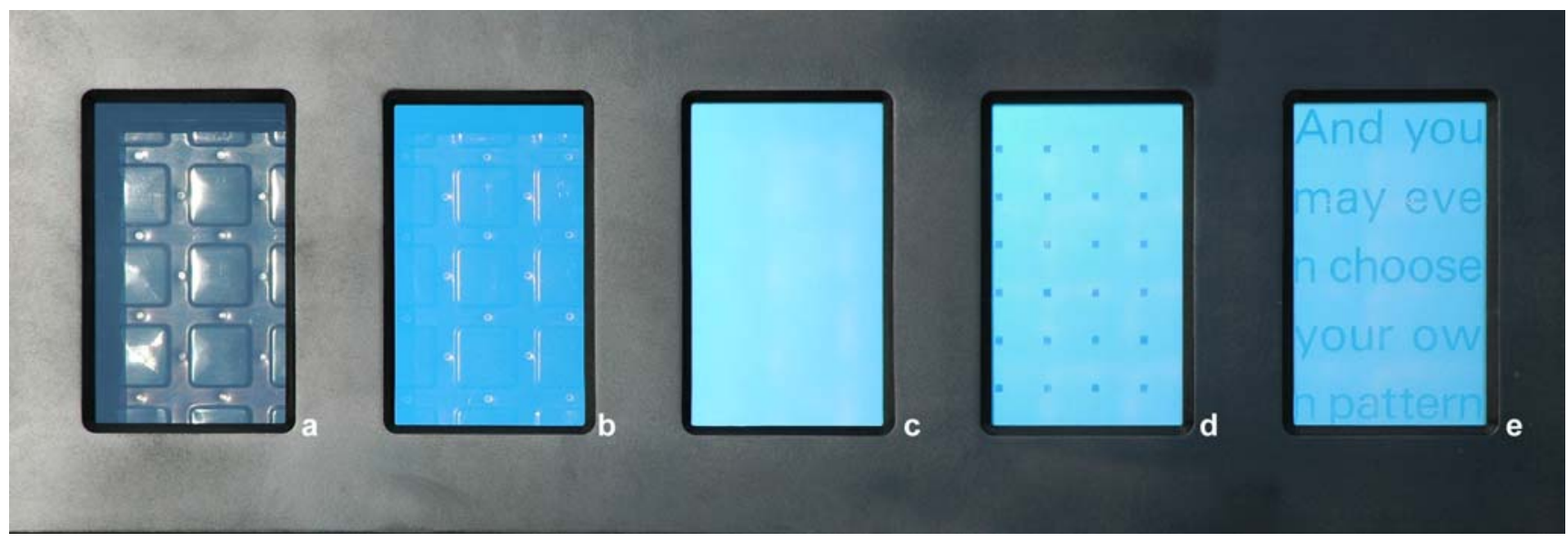

Fig.5: Impact of various tested glazing treatments on the visibility of a standard black solar absorber: $a$. Standard extra white transparent glazing; b. Blue selective coating on extra white glazing; $c$. Blue selective coating (inner side) + frosted treatment (outer side); d. Blue selective coating + standard patterned acid etching; e. Blue selective coating+ custom acid etching. 

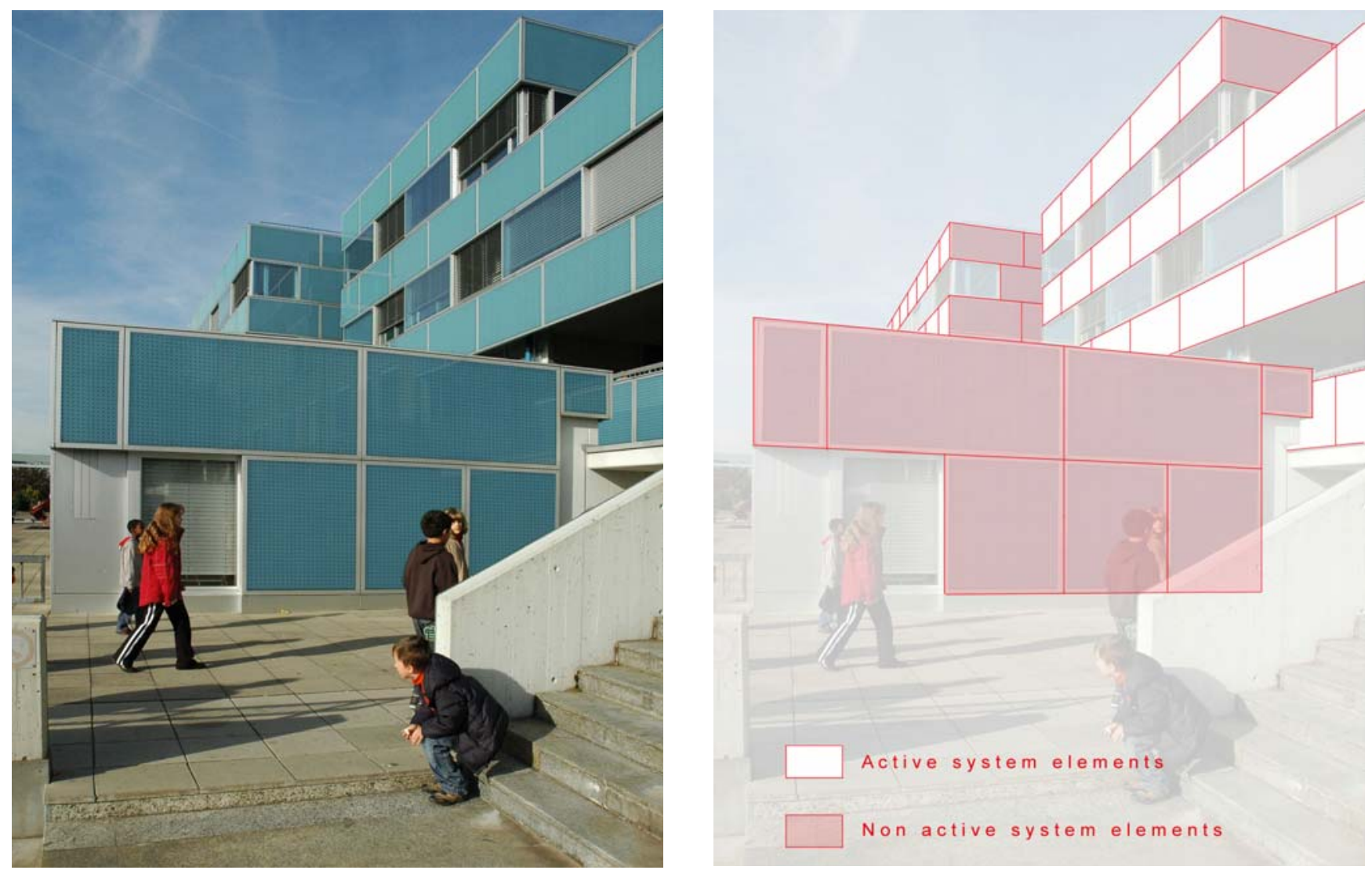

Figure 8 a: LESO glazing integration simulation over Pully school (CH); 8-b: Active and non active areas.

\section{CONCLUSIONS}

Integration of solar thermal collectors into facades will soon become crucial as one answer to the growing demand of solar energy in buildings. As the present situation shows, the general very low quality of the existing collectors' integration limits their use to a small portion of the building stock. The newly developed glazing aims at helping to unlock this situation by modifying the global aspect of solar collectors: the black absorber and its visual defects can be hidden by a coloured glass, whose texture can be used from an architectural point of view. As the same glass can cover active and non active areas, the architect will be free to choose a coherent part of the facade to be clad, and equip only the thermally needed portion with absorbers.

\section{ACKNOWLEDGMENTS}

This work was supported by the Swiss Federal Office for Energy. The Authors would like to thank the Companies Glas Trösch AG for their help in producing large glass coatings on their facility and Schweizer Metallbau AG for offering real size collectors for testing.

\section{REFERENCES}

1. Bergmann I., Facade integration of solar thermal collectors - A new opportunity for planners and architects. Renewable Energy World, 5(3), 89-97, 2002.

2. Hestnes A.G., Building integration of solar energy systems, in Solar Energy, 67 (4-6), 181-187, 2000.

3. Krippner, R., Herzog, T., 2000. Architectural aspects of solar techniques - Studies on the integration of solar energy systems. In Proceedings EUROSUN 2000, $3^{\text {rd }}$ ISES-Europe Solar Congress, Cophenagen.

4. Munari Probst MC., Roecker C., Toward an improved quality of building integrated solar thermal systems, Sol. Energy (2007), doi: 10.1016/ j.solener.2007.02.009

5. Schueler A. et al., Potential of quartwave interference stacks for coloured thermal solar collectors, Sol. Energy 79-2005

6. Munari Probst MC., Roecker C., Schueler A., Impact of new developments on the integration into facades of solar thermal collectors, in Proceedings EUROSUN 2004, Freiburg im Breisgau, Germany, 2004.

7. Schueler A. et al., Thin film multilayer design types for coloured glazed thermal solar collectors, Solar Energy Materials \& Solar Cells 89 (2005) 219-231. 